\title{
Perceptual grouping and visual selective attention
}

\author{
ELAINE FOX \\ University of Essex, Colchester, England
}

\begin{abstract}
The present study demonstrates that incongruent distractor letters at a constant distance from a target letter produce more response competition and negative priming when they share a target's color than when they have a different color. Moreover, perceptual grouping by means of color, attenuated the effects of spatial proximity. For example, when all items were presented in the same color, near distractors produced more response competition and negative priming than far distractors (Experiment 3A). However, when near distractors were presented in a different color and far distractors were presented in the same color as the target, the response competition $\times$ distractor proximity interaction was eliminated and the proximity $\times$ negative priming interaction was reversed (Experiment $3 \mathrm{~B}$ ). $\mathrm{A}$ final experiment demonstrated that distractors appearing on the same object as a selected target produced comparable amounts of response competition and negative priming whether they were near or far from the target. This suggests that the inhibitory mechanisms of visual attention can be directed to perceptual groups/objects in the environment and not only to unsegmented regions of visual space.
\end{abstract}

Several lines of evidence indicate that visual attention can be directed to unparsed regions of visual space. For example, subjects are faster to detect objects that appear in cued relative to uncued locations (Posner, 1980), and distractors that are close to a target object produce more interference than distractors that are farther away from the target (B. A. Eriksen \& C. W. Eriksen, 1974). To illustrate, in the flanker task subjects are required to respond to centrally located letters while ignoring spatially separate distracting letters. The typical finding is that response-incongruent distractors slow reaction times (RTs) relative to trials containing response-congruent distractors. However, it has been shown that response competition from incongruent distractors is apparent only if the distracting letters are close to the target letter; beyond about $1^{\circ}$ of visual angle, response-incongruent distractors have little effect (see, e.g., B. A. Eriksen \& C. W. Eriksen, 1974; C. W. Eriksen \& St. James, 1986; but see Miller, 1991). Such findings have led to the view that visual attention may be like a "spotlight" that illuminates or a "zoom lens" that magnifies a particular region of visual space (see, e.g., B. A. Eriksen \& C. W. Eriksen, 1974; C. W. Eriksen \& St. James, 1986; C.W. Eriksen \& Yeh, 1985; Posner, 1980).

The notion that spatial location is special in visual selection was also supported by the results of Tsal and Lavie (1988). They presented subjects with a circular array con-

The research reported here was partially supported by a University of Essex Research Promotion Fund grant. I am grateful to Jan-Willem de Fockert and Phil Badcock for help with data collection. Thanks are also due to Lisa Fournier, Luis Fuentes, Steve Tipper, and two anonymous reviewers for helpful comments on an earlier version of this paper. Portions of the data presented here were reported at the 1995 spring meeting of the Experimental Psychology Society, University of Cambridge, England. Correspondence should be addressed to E. Fox, Department of Psychology, University of Essex, Wivenhoe Park, Colchester CO4 3SQ, U.K. (e-mail: efox@essex.ac.uk). taining nine letters with three letters presented in red, three in green, and three in brown. Letters in the same color were never adjacent and the task was (1) to report a single letter of a given color (e.g., a green letter) and then (2) to report any other letters they could identify. The results clearly showed that subjects tended to report additional letters that were adjacent to the first named letter. The authors interpreted this as evidence that directing attention to a spatial location is a mandatory process that takes place regardless of the dimension on which the letter was initially selected (e.g., color).

However, some investigators have questioned whether spatial location plays a unique role in directing visual attention (e.g., Kanwisher \& Driver, 1992). Several results suggest that early visual processes segment the visual scene into separate objects and/or perceptual groups (Marr, 1982). The logic is that later attentional processes can then be directed to these objects or perceptual groups regardless of their spatial characteristics (see, e.g., Duncan, 1984; Kanwisher \& Driver, 1992). An experimental task described by Duncan was influential in the development of this object-based view of attention. Duncan presented subjects with displays that consisted of two overlapping objects such as a box with a line struck through the box. Both the box and the line could vary on two dimensions: The box could be either large or small and have a gap on the left or right, and the line could be either dotted or dashed and be tilted either clockwise or counterclockwise. The critical finding was that subjects could judge two properties of the same object (e.g., "left" and "large" for the box) as easily as judging one property. However, if subjects had to judge two properties from different objects (e.g., "left" for the box, and "dotted" for the line), there was a significant decrement in performance. Thus, subjects were more accurate when reporting two properties of a single object than when reporting two properties of different objects. This result is difficult to recon- 
cile with the spotlight model of attention since the two objects were superimposed in the same spatial region. Duncan concluded that visual attention is primarily object based rather than space based (see Baylis \& Driver, 1993, for further evidence).

Converging evidence for an object-based view comes from a study reported by van der Heijden, Kurvink, de Lange, de Leeuw, and van der Geest (1996). They presented subjects with the same task as that used by Tsal and Lavie (1988) with the modification that subjects now had to name a centrally located digit in order to force subjects to focus attention on the center of the display. As before, subjects had to name a letter of a given color (following the digit naming task) and then name as many other letters as they could. In several experiments, they found that subjects now tended to report letters in the same color as the first named letter rather than adjacent (different colored) letters, as found by Tsal and Lavie. These results strongly suggest that the attribute of color may influence attention very much like spatial location does. In other words, location may not be unique in directing visual attention (Kanwisher \& Driver, 1992; van der Heijden et al., 1996).

Further evidence for object-based attention comes from studies using variants of the flanker paradigm. For example, Harms and Bundesen (1983) presented a target letter at fixation that was flanked on either side by either same-color or different-color distractor letters. Stronger response competition was found in same-color relative to different-color conditions, indicating that incongruent distractors produced more interference when they were grouped with the target on the basis of common color. Humphreys (1981) also found that a color difference between target and distractor elements improved selective attention to the targets. The task was to decide whether a cued target line was curved to the left or to the right while ignoring a distracting line that was curved in either a congruent or an incongruent direction. Response competition in this task occurred only when the target and distractor lines were the same color and not when they were different colors (Humphreys, 1981, Experiment 1).

Conceptually similar results were found in an elegant study reported by Driver and Baylis (1989). They demonstrated that distant distractor letters that shared a common motion with a target letter produced greater response competition than distractors that were closer to the target but did not share the target's motion. This result is difficult for a spotlight model of attention to explain since far distractors produced more response competition than near distractors. This work has been extended by Baylis and Driver (1992), who found that perceptual grouping of targets and distractors by means of color or good continuation can also override the effects of spatial proximity. For example, in one experiment subjects were required to respond to a target letter at fixation while ignoring irrelevant distractor letters at a near or a far spatial separation from the target. Distant distractors that were the same color as a target letter produced greater response competition than near distractors that were in a different color (Baylis \& Driver, 1992, Experiment 2). Thus, perceptual segregation of targets and distractors by means of color can improve the efficiency of visual selection (Baylis \& Driver, 1992; Harms \& Bundesen, 1983; Humphreys, 1981). Moreover, the impact of perceptual grouping factors can sometimes actually override the impact of spatial proximity (Baylis \& Driver, 1992; Driver \& Baylis, 1989).

In the studies just mentioned, versions of the flanker task were presented in which distracting elements were perceptually segregated from the target element on the basis of color or common motion (Baylis \& Driver, 1992; Driver \& Baylis, 1989; Harms \& Bundesen, 1983; Humphreys, 1981). Kramer and Jacobson (1991) presented a version of the flanker task in which distracting elements formed either part of the same object as the target or part of a different object. The task was to decide whether a target line at fixation was dotted or dashed. Distracting lines (congruent or incongruent with the target) were presented either to the right or to the left of fixation. The critical finding was that response competition was greater when the distracting lines (to the left or right) were part of the same object as the target line (connected to it by horizontal lines), relative to when the distracting lines were parts of different objects.

In summary, it seems that the amount of response competition produced by incongruent distractors is not solely a function of their distance from a target. Distractors that are grouped with the target because of common motion, common color, or good continuation will generally produce more response competition than distractors that are easily segregated from the target (Baylis \& Driver, 1992; Driver \& Baylis, 1989; Harms \& Bundesen, 1983; Humphreys, 1981; Kramer \& Jacobson, 1991; but see Kramer, Tham, \& Yeh, 1991, for contrasting results). As pointed out by Baylis and Driver (1992), these results imply that visual attention is directed to perceptual groups derived from a segmentation of a visual display according to Gestalt principles of perceptual organization, rather than directed to unparsed regions of the visual field (see Tsal \& Lavie, 1988; van der Heijden et al., 1996). On this view, spatial proximity is simply another grouping factor, albeit a very powerful one. Lavie and Driver (1996) have recently presented data from a novel paradigm showing that object-based limits on divided attention can operate even across distances of up to about $8^{\circ}$ of visual angle. However, they also found that when subjects were cued to expect targets in a narrow region of the display, the object-based effect was eliminated. This result indicates that object-based selection may operate only within spatially attended regions. Taken together, the research literature indicates that visual selection is not either location based or object based, but rather, spatial and object factors may interact in complex ways in determining the nature and direction of visual selection.

Given the evidence for object-based selection just reviewed, it would be expected that perceptual grouping 
should also influence the inhibitory mechanisms underlying visual selection (see, e.g., Houghton \& Tipper, 1994). Inhibitory processes in visual selective attention are generally inferred from the phenomenon of negative priming (Tipper, 1985). To illustrate, if a distracting element in the flanker task becomes a target on the following trial, people take longer to respond relative to when the target has not been previously presented (see, e.g., DalrympleAlford \& Budayr, 1966; Neill, 1977). This negative priming effect has been interpreted as evidence that distracting objects are actively inhibited during the process of target selection (e.g., Neill, 1977; Neill \& Westberry, 1987; Tipper, 1985; Tipper \& Cranston, 1985). The argument is that efficient selection is achieved by actively suppressing distractor elements on a prime trial (which is equivalent to the usual flanker task), and that this inhibition then carries forward to the subsequent probe trial. This forward-acting inhibition produces longer RTs when recently ignored items have to be responded to. Negative priming is a robust phenomenon and has been demonstrated across a wide variety of tasks and stimuli (for recent literature reviews, see Fox, 1995a; May, Kane, \& Hasher, 1995; Neill \& Valdes, 1996; Neill, Valdes, \& Terry, 1995; Tipper \& Milliken, 1996).

The primary aim of the present study was to determine whether the perceptual grouping of a scene has a strong impact on the inhibitory mechanisms of visual selection as indexed by negative priming. No study has systematically investigated the role of perceptual grouping or "objectness" in negative priming. In previous research, it has been shown that distracting letters produce more response competition and negative priming as they are moved closer to a target letter (Fox, 1994, Experiment 1). This result, however, may indicate either that spatially proximal elements are naturally grouped together and thus that grouping affects the two measures of distractor processing, or that spatially proximal items produce stronger effects because attention is influenced primarily by items falling within the putative spotlight. Thus, space- and object-based accounts cannot be distinguished on the basis of the results reported by Fox (1994).

In another study, it was shown that segregating target and distractor elements by means of color significantly reduces response competition, but has little impact on negative priming (Driver \& Tipper, 1989). The task was to count the number of red letters in arrays of red letters and black digits. Even though ignored black digits produced no response competition on the counting response, these same distractors produced significant negative priming on the subsequent probe trial. In a second experiment, the irrelevant digits were printed in red rather than black and once again the task was to count the number of red letters present. In this case, significant response competition was found, which is consistent with previous research (e.g., Harms \& Bundesen, 1983; Humphreys, 1981). The surprising result, however, was that the magnitude of negative priming was about the same as in the first experiment (Driver \& Tipper, 1989, Experiment 2). Thus, perceptual segregation of target and distractor elements by color reduced the magnitude of response competition, while the magnitude of negative priming remained constant.

This was the starting point for the present investigation. The aim was to examine the influence of perceptual grouping on negative priming in more detail. Given the strong impact of grouping factors on response competition (see, e.g., Baylis \& Driver, 1982; Driver \& Baylis, 1989; Harms \& Bundesen, 1983; Humphreys, 1981), it seemed surprising that negative priming would be relatively immune to nonspatial grouping factors such as color (Driver \& Tipper, 1989). In contrast, it has been found that spatial proximity has equivalent effects on measures of both response competition and negative priming (Fox, 1994). This discrepancy may indicate that Fox's (1994) results were due to spatial proximity per se rather than to grouping by means of common location. Thus, it is important to investigate the influence of perceptual grouping on the inhibitory mechanisms of visual selection by manipulating nonspatial grouping factors (e.g., color, same-different objects).

\section{EXPERIMENT 1}

Following Tipper, MacQueen, and Brehaut (1988), pairs of letters (A, B, C, or D) were presented on prime and probe displays and the subject's task was to identify the letter indicated by an adjacent bar marker. Response competition was measured on prime trials and negative priming was measured on probe trials. Perceptual grouping of target and distractor elements was manipulated on the prime trials only. In one condition, prime targets were presented in black and irrelevant distractors were presented in black (same-color distractor). In the other condition, prime targets were presented in black and irrelevant distractors were presented in red (different-color distractor). All of the probe displays contained a black target and a black distractor. The prediction from previous research using the response competition paradigm (e.g., Baylis \& Driver, 1992) is that a greater magnitude of response competition should be observed from distractors that share a common color with the target relative to distractors with a different color from that of the target object. If grouping by means of common color does not influence negative priming, as suggested by the results of Driver and Tipper (1989), then grouping on the prime display should not affect negative priming. However, if grouping on the prime display does influence negative priming (see, e.g., Fox, 1994), then greater negative priming should be observed on same-color trials relative to different-color trials.

\section{Method}

Subjects. Twelve undergraduate students at University College Dublin participated in this experiment. Subjects were between 18 
and 26 years of age and reported normal or corrected-to-normal vision. Each subject was paid IR $f 3.00$ for participation in a single experimental session lasting about $45 \mathrm{~min}$.

Apparatus and Stimuli. Stimulus presentation and data collection were controlled by a Macintosh LC 4 computer connected to a color monitor. Target and distractor stimuli were the capital letters $A, B, C$, and D, each subtending approximately $1.9^{\circ}$ of vertical and $1.3^{\circ}$ of horizontal visual angle at a viewing distance of about $60 \mathrm{~cm}$. The prime display always presented the two letters side by side with a bar marker appearing on the outside of the letter to indicate the target (-A A or A A-). The probe display always presented the letters one above the other with the bar marker appearing to the left of the target letter. Letter pairs were about $3.3^{\circ}$ of visual angle apart on the horizontal axis (prime display) and $3.3^{\circ}$ of visual angle apart on the vertical axis (probe display). In the same-color condition, the prime display targets and distractors were always presented in black on a light gray background. In the different-color condition, the target was always presented in black while the distractors were always presented in red on a light gray background. Probe display targets and distractors were always presented in the same color.

Design and Procedure. Each trial consisted of a prime and a probe display, with every display containing two letters. As in Tipper et al. (1988), response competition was assessed by comparing a condition in which a target (specified by an adjacent bar marker) and a distractor letter had the same identity (i.e., congruent; e.g., -B B) with a condition in which the target and distractor letters had different identities (i.e., incongruent; e.g., -C A). Response competition is indicated by longer RTs in the latter condition.

The priming effects of the ignored distractor were assessed in the subsequent probe trial. The probe stimulus always contained a target and a distractor letter with different identities. There were three priming conditions. Probe trials followed congruent prime trials (e.g., D D- followed by -C B; this condition was necessary given the design, but was of no theoretical interest and thus was not included in the analysis). In the control (C) condition, the probe trials following incongruent prime trials contained target and distractor letters that were different from the prime display (e.g., - A C followed by D B-). Finally, in the ignored repetition (IR) condition, the distractor in the prime display had the same identity as the target in the subsequent probe display (e.g., -B A followed by C A-).

The similarity (or grouping) of the target and distractor letters (in terms of color) was manipulated within subjects. Target distractor grouping (same or different colors) was manipulated only on the prime display (in separate blocks of trials). The experiment had a fully within-subjects design with each subject completing six blocks each of which contained 96 pairs of trials (i.e., prime and probe trials). Each subject completed three blocks of same-color distractor trials and three blocks of different-color distractor trials. The first of each set of three blocks was considered practice and was not analyzed. The order of each set of blocks (same- vs. different-color distractor blocks) were counterbalanced across subjects; 6 subjects received the three same-color distractor blocks followed by the three different-color distractor blocks. The other 6 subjects received the reverse order.

Subjects were informed that they would be dealing with four letters: A, B, C, and D. These letters were printed in black tape on the $\mathrm{D}, \mathrm{F}, \mathrm{J}$, and $\mathrm{K}$ keys of a standard computer keyboard, respectively. The subjects were encouraged to respond to the letter with the bar marker beside it as quickly as possible by pressing the appropriate key, while trying not to make mistakes. Subjects used the index and middle fingers of each hand to make their responses. A trial was considered correct only if both the prime and the probe displays received correct responses.

The sequence of events within a trial was as follows: A fixation point $(+)$ was presented at the center of the screen for $500 \mathrm{msec}$. The prime display was then presented centrally for $150 \mathrm{msec}$. The prime display was followed by a blank screen until a response was made. Following the response, there was a blank screen for $350 \mathrm{msec}$ and then the probe display was presented centrally for $150 \mathrm{msec}$. This was followed by a blank screen until a response was made. There was an intertrial interval of $2 \mathrm{sec}$.

\section{Results}

Prime data. Trials containing errors or with RTs less than 100 msec or greater than $1,500 \mathrm{msec}$ on the prime display were excluded from the data set. The means of the remaining median correct RTs for the prime displays are presented in Figure 1. The median correct RTs were analyzed by means of a 2 (grouping: same vs. different) $\times 2$ (response competition: congruent vs. incongruent) analysis of variance (ANOVA) with subjects as a random factor. There were main effects of grouping $[F(1,11)=$ $14.9, M S_{\mathrm{e}}=180.1, p<.01$; slower RTs on same-color distractor trials] and for response competition $[F(1,11)=$ $83.9, M S_{\mathrm{e}}=153.5, p<.001$; slower RTs on incongruent trials]. There was also a significant grouping $\times$ response competition interaction $\left[F(1,11)=20.9, M S_{\mathrm{e}}=63.4\right.$, $p<.001]$. Planned comparisons revealed that $\mathrm{RT}$ s on incongruent trials were slower than RTs on congruent trials (both when the target and distractor were presented in the same color [ $43 \mathrm{msec}: t(11)=8.55, p<.001$ ] and when they were in different colors [22 msec: $t(11)=4.4, p<$ $.0011)$. The interaction indicates that the response competition effect was larger in the same-color distractor conditions.

The mean error rates for each of the prime trial conditions are shown in Table 1 (Experiment 1). The arcsin transformations of these error rates were subjected to a 2 (grouping: same vs. different) $\times 2$ (response competition: congruent vs. incongruent) ANOVA with subjects as a random factor. There were main effects of grouping $\left[F(1,11)=16.8, M S_{\mathrm{e}}=0.010, p<.01 ;\right.$ more errors in same-color distractor condition] and of response competition $\left[F(1,11)=15.0, M S_{\mathrm{e}}=0.013, p<.01\right.$; more errors on incongruent trials]. As in the RT analysis, there was

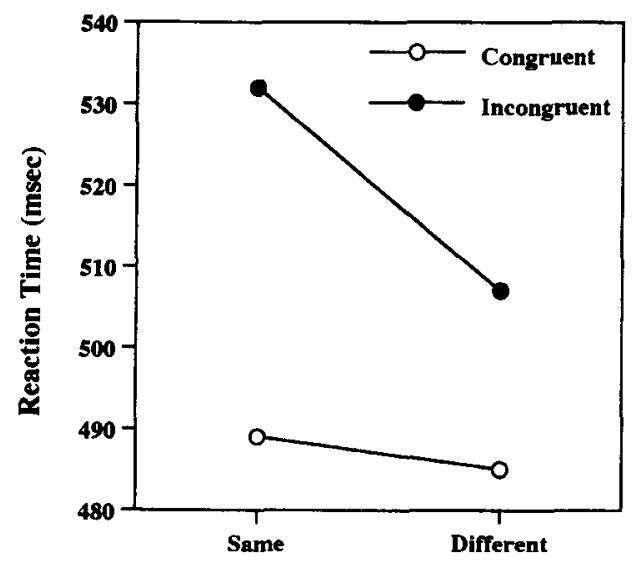

Target-Distractor Color

Figure 1. Means of median correct reaction times for prime displays in Experiment 1. 
Table 1

Mean Error Rates on Prime and Probe Displays in Experiments 1 and 2

\begin{tabular}{lcc}
\hline \multicolumn{1}{c}{ Display } & \multicolumn{2}{c}{ Prime Target-Distractor Color } \\
\cline { 2 - 3 } & Same & Different \\
\hline Prime & Experiment 1 & \\
$\quad$ Congruent & .02 & .02 \\
Incongruent & .06 & .03 \\
Probe & & \\
$\quad$ Control & .02 & .03 \\
Ignored repetition & .03 & .03 \\
& Experiment 2 & \\
Prime & & \\
Congruent & .02 & .02 \\
Incongruent & .03 & .03 \\
Probe & & .03 \\
$\quad$ Control & .04 & \\
Ignored repetition & .04 & \\
\hline
\end{tabular}

also a significant grouping $\times$ response competition interaction $\left[F(1,11)=9.5, M S_{\mathrm{e}}=0.003, p<.01\right]$. Further analysis revealed that subjects made more errors on incongruent trials only when the target and distractor shared the same color $[t(11)=3.8, p<.01]$ and not when the target and distractor were in different colors $[t(11)=$ 1.64, n.s.].

Probe data. Trials with errors on either the prime display or the probe display were excluded from the data analysis. Trials with RTs less than 100 or greater than $1,500 \mathrm{msec}$ were also excluded. The median correct RTs for the $\mathrm{C}$ and IR probe displays are presented in Figure 2. The median correct RTs on probe trials were subjected to a 2 (grouping: same vs. different) $\times 2$ (negative priming: $C$ vs. IR) ANOVA with subjects as a random factor. It should be noted that "grouping" refers to grouping on the prime trial. There were main effects of grouping $[F(1,11)$ $=16.0, M S_{\mathrm{e}}=134.3, p<.01$; slower RTs on probe trials following same-color distractor prime trials] and of negative priming $\left[F(1,11)=11.6, M S_{\mathrm{e}}=122.6, p<.01\right.$; slower RTs on IR trials]. Of more theoretical interest, there was also a significant grouping $\times$ negative priming interaction $\left[F(1,11)=23.8, M S_{\mathrm{e}}=40.4, p<.001\right]$. Planned comparisons revealed that negative priming occurred only following prime trials in which the target and distractor were presented in the same color $[20 \mathrm{msec}$ : $t(11)=4.4, p<.001]$ and not when the previous prime trial contained a target and distractor in different colors [2 msec: $t(11)<1$ ].

The mean error rates for each probe trial condition are shown in Table 1 (Experiment 1). The arcsin transformations of these error rates were subjected to a 2 (grouping: same vs. different) $\times 2$ (negative priming: $C$ vs. IR) ANOVA with subjects as a random factor. The only main effect to reach significance was negative priming $[F(1,11)$ $=22.2, M S_{\mathrm{e}}=.002, p<.001 ;$ more errors on IR trials]. As in the RT analysis, there was a significant grouping (on the prime trial) $\times$ negative priming interaction $[F(1,11)=$ $\left.8.6, M S_{\mathrm{e}}=.002, p<.05\right]$. Further analysis revealed that subjects made more errors on IR trials only when the previous prime trial contained a target and distractor that shared the same color $[t(11)=5.4, p<.001]$ and not when the prime trial contained a target and distractor in different colors $[t(11)=1.26$, n.s. $]$.

\section{Discussion}

The results of Experiment 1 are straightforward. Presenting target and distractor letters on a prime display in the same color increased the magnitude of both response competition and negative priming. The results replicate previous findings that distractors at a constant distance from a target produce more response competition if they are grouped with the target by means of common color (Baylis \& Driver, 1992). However, contrary to what might have been expected from the results of Driver and Tipper (1989), the present experiment revealed that grouping by means of common color on the prime display also had a strong effect on subsequent negative priming. Targets and distractors that shared a common color on the prime display produced substantially greater negative priming on the probe display than items that were presented in different colors. Thus, grouping on the prime display by means of spatial proximity (Fox, 1994) or common color (present experiment) is an important determinant of negative priming. The present results also add to the evidence that there is a positive relation between measures of response competition and negative priming. This suggests that inhibition may be reactive to the amount of response competition occurring on the prime trial.

These results suggest that perceptual grouping by means of common color is an important determinant of selective attention as measured by both response competition and negative priming. However, there is an alternative explanation for the results of Experiment 1 . Since the prime target was always presented in the same color (black), subjects may have used color as a selection cue in addition

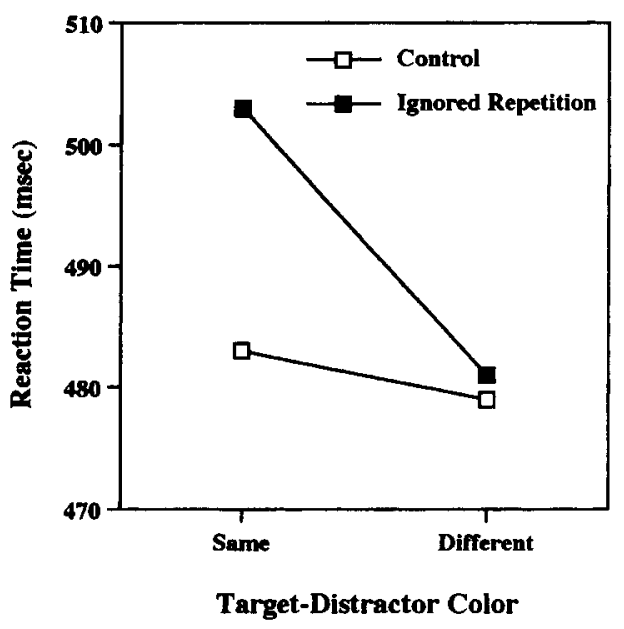

Figure 2. Means of median correct reaction times for probe displays in Experiment 1. 
to the bar marker. This would result in very efficient selection on different-color trials but would lead to more disruption on same-color displays since the distractor now shares a selection feature with the target. This mechanism would explain the finding of less response competition and negative priming on different-color relative to samecolor prime displays. One way to avoid this problem is to vary the color grouping manipulation randomly on a trialto-trial basis so that color cannot be used as a selection cue. This was the aim of Experiment 2.

\section{EXPERIMENT 2}

Experiment 2 was also a letter classification task in which subjects were required to respond to centrally located target letters while ignoring flanking letters to the left and right on prime and probe displays. The target letters on prime displays were randomly presented in either red or green and the distracting letter was either in the same color as the target or in the other color. All letters on the probe displays were in the same color and this was determined by the color of the target letter on the previous prime display. For example, a red target (with either red or green distractors) presented on the prime display was always followed by a probe display containing a red target and red distractors. Likewise, a green prime target (with either green or red distractors) was always followed by a probe display containing green target and distractor letters. Because prime target letters were always presented at fixation and could appear in either color, it was expected that color would not be a useful selection cue. Therefore, replication of the interactions between perceptual grouping and response competition and negative priming that were observed in Experiment 1 would provide stronger evidence that perceptual grouping is an important determinant of selective attention.

\section{Method}

Subjects. Twenty-four students at the University of Essex participated in the experiment for course credit. Subjects were between 18 and 39 years of age and reported normal or corrected-to-normal vision. Each subject took part in a single experimental session lasting about $40 \mathrm{~min}$.

Apparatus and Stimuli. Stimulus presentation and data collection were controlled by an IBM-compatible microcomputer running MEL software (Schneider, 1988). Target and distractor stimuli were the capital letters $\mathrm{A}, \mathrm{B}, \mathrm{C}$, or $\mathrm{D}$, each subtending about $.51^{\circ}$ of vertical and $.25^{\circ}$ of horizontal visual angle at a viewing distance of approximately $45 \mathrm{~cm}$. Letters were always presented in triplets with the target letter in the middle at fixation flanked on either side by the same distractor letter (e.g., ABA). The horizontal visual angle of the entire letter triplet was about $1.5^{\circ}$. Target and distractor letters were presented in either red or green (MEL color codes 4 and 2 , respectively).

Design and Procedure. The experimental design was completely within subjects. The factor of grouping related only to the prime display; on half of the trials, the target and distractors were in the same color (e.g., red target and red distractors), while in half of the trials, distractors were in a different color (e.g., red target and green distractors). The other two factors were similar to those of Experiment 1 : response competition (congruent vs. incongruent prime displays) and negative priming ( $\mathrm{C}$ vs. IR probe displays). All of these within-subjects factors were completely randomized. Each subject completed five blocks of 96 trials. The first block of trials was considered practice, so subjects completed 384 experimental trials in total. There were 192 congruent prime displays, with half of these being same-color trials (i.e., target and distractor in the same color) and half being different-color trials (i.e., target and distractor in different colors). Half of each of these conditions had red target letters and half had green target letters. The breakdown was similar for the 192 incongruent prime displays. The 192 probe displays following congruent prime displays were not included in the analysis. Of the 192 probe displays following incongruent prime displays, 96 were $C$ and 96 were IR. Half of all the $C$ probe displays followed same-color prime displays ( 24 with red targets, 24 with green targets) and half followed different-color prime displays ( 24 with red targets, 24 with green targets). The breakdown was the same for the IR trials.

Subjects were informed that they would be dealing with four letters- A, B, C, and D. These letters were printed in black tape on the $1,2,9$, and 0 keys at the top of a standard computer keyboard, respectively. The subjects were encouraged to respond to the central letter as quickly as possible by pressing the appropriate key, while trying not to make mistakes. Subjects used the index and middle fingers of each hand to make their responses. A trial was considered correct only if both the prime and the probe displays received correct responses.

The sequence of events within each trial was as follows: A fixation point $(+)$ was presented at the center of the computer screen for $500 \mathrm{msec}$. This display was replaced by the prime display, which was presented for $180 \mathrm{msec}$. This was followed by a blank screen until a response was made or until $2,000 \mathrm{msec}$ had elapsed. Following the response (or after $2,000 \mathrm{msec}$ ), there was a blank screen for $300 \mathrm{msec}$, and then the probe display was presented in the same location for $180 \mathrm{msec}$. A blank screen was presented until a response was made or until $2,000 \mathrm{msec}$ had elapsed. There was an intertrial interval of $800 \mathrm{msec}$.

\section{Results}

Prime data. Trials containing errors or with RTs less than 100 or greater than $1,500 \mathrm{msec}$ on the prime display were excluded from the data set. The means of the remaining median correct RTs for the prime displays are presented in Figure 3. The median correct RTs were an-

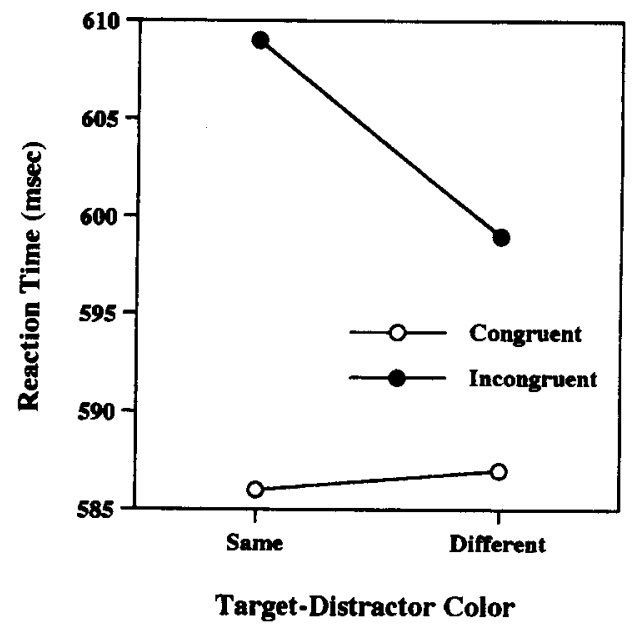

Figure 3. Means of median correct reaction times for prime displays in Experiment 2. 
alyzed by means of a 2 (target color: red vs. green) $\times 2$ (grouping: same vs. different) $\times 2$ (response competition: congruent vs. incongruent) ANOVA with subjects as a random factor. The only main effect to reach significance was response competition $\left[F(1,23)=18.9, M S_{\mathrm{e}}=740.9\right.$, $p<.001]$; RTs were longer on incongruent $(604 \mathrm{msec})$ than on congruent $(587 \mathrm{msec}$ ) prime displays. There was an unexpected target color $\times$ grouping interaction $\left[F(1,23)=4.33, M S_{\mathrm{e}}=269.4, p<.05\right]$. When prime targets were red, RTs were the same regardless of whether the distractors were red $(597 \mathrm{msec})$ or green $(597 \mathrm{msec})$. However, when the prime target was green, RTs were faster when the distractors were red $(589 \mathrm{msec})$ than when the distractors were green $(598 \mathrm{msec})$. The predicted grouping $\times$ response competition interaction approached significance $\left[F(1,23)=3.99, M S_{\mathrm{e}}=408.3\right.$, $p<.06]$. Further analysis revealed that response competition was significant for both same-color $[t(23)=4.6$, $p<.001]$ and different-color $[t(23)=2.33, p<.02]$ conditions. However, as expected, the magnitude of response competition in the same-color condition $(23 \mathrm{msec})$ was larger than that observed in the different-color $(12 \mathrm{msec})$ condition $[t(23)=2.00, p<.03]$. Although not significant, there was a trend toward a three-way target color $X$ grouping $\times$ response competition interaction $[F(1,23)=$ $\left.3.5, M S_{\mathrm{e}}=180.6, p<.08\right]$. This was due to the predicted grouping $\times$ target color interaction being much stronger when the target color was red (response competition of 29 and $10 \mathrm{msec}$ for same- and different-color conditions) than when the target color was green (response competition of 16 and $13 \mathrm{msec}$ for same- and different-color conditions, respectively).

The mean error rates for each of the prime trial conditions are shown in Table 1 (Experiment 2). The arcsin transformations of these error rates were subjected to a 2 (target color: red vs. green) $\times 2$ (grouping: same vs. different) $\times 2$ (response competition: congruent vs. incongruent) ANOVA with subjects as a random factor. The only effect to reach significance was a main effect of response competition $\left[F(1,23)=4.7, M S_{\mathrm{e}}=0.046, p<.04\right]$; more errors occurred on response-incongruent (.03) than on response-congruent trials $(.02)$.

Probe data. Trials with errors on either the prime display or the probe display were excluded from the data analysis, as were trials with RTs less than 100 or greater than 1,500 msec. The median correct RTs for the $\mathrm{C}$ and IR probe displays are presented in Figure 4. The median correct RTs on probe trials were subjected to a 2 (target color: red vs. green) $\times 2$ (grouping: same vs. different) $\times 2$ (negative priming: $C$ vs. IR) ANOVA with subjects as a random factor. As in Experiment 1, "grouping" refers to grouping by means of common color on the prime trial. The only effect to reach significance was a grouping $x$ negative priming interaction $\left[F(1,23)=5.5, M S_{\mathrm{e}}=\right.$ $762.93, p<.03$ ]. Planned comparisons revealed that negative priming occurred only following prime trials in which the target and distractor were presented in the same color [14 msec: $t(23)=2.3, p<.02]$. The slight facilita-

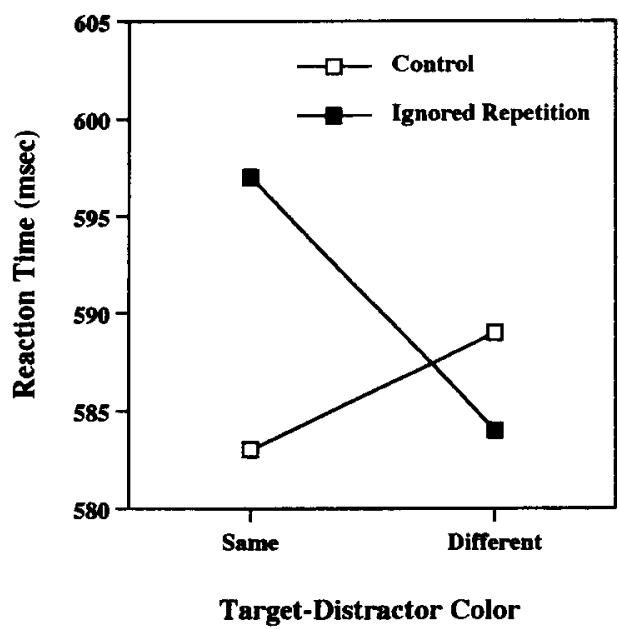

Figure 4. Means of median correct reaction times for probe displays in Experiment 2.

tion that occurred when the previous prime trial contained a target and distractor in different colors was not significant [5 msec: $t(23)<1]$.

The mean error rates for each probe trial condition are shown in Table 1 (Experiment 2). The arcsin transformations of these error rates were subjected to a 2 (target color: red vs. green) $\times 2$ (grouping: same vs. different) $\times 2$ (negative priming: $C$ vs. IR) ANOVA with subjects as a random factor. The only effect to reach significance was a main effect of grouping $\left[F(1,23)=8.22, M S_{\mathrm{e}}=\right.$ $0.042, p<.001$ ]; subjects made more errors on probe trials following same-color prime trials (.04) than following different-color prime trials (.03).

\section{Discussion}

Experiment 2 manipulated perceptual grouping by randomly intermixing same- versus different-color prime displays in a selective attention task. This procedure ensured that subjects could not use target color as a selection cue since the target (which always appeared at fixation) could appear randomly in either red or green. The results showed that prime displays that contained a target and distracting letters in the same color produced more response competition than prime displays containing a target and distracting letters in different colors. On subsequent probe displays, it was found that the magnitude of negative priming was substantially larger following prime displays with targets and distractors in the same color. No negative priming was observed following prime displays in which target and distracting letters were in different colors. Thus, on two separate measures (response competition and negative priming), it appears that perceptual grouping is an important determinant of selective attention. These results extend the work of Baylis and Driver (1992) in two ways. First, these results demonstrate that perceptual grouping can influence response competition even when grouping is manipulated randomly 
on a trial-to-trial basis. This is an important demonstration; previous work is open to the criticism that subjects may have used color as an additional selection cue since target color was always constant (e.g., Baylis \& Driver, 1992; present Experiment 1).

Second, the present results demonstrate that negative priming as well as response competition is influenced to a significant extent by grouping on prime displays. This result contrasts with those reported by Driver and Tipper (1989), who found that perceptual grouping by means of common target-distractor color on prime displays had little influence on subsequent negative priming. The task used by Driver and Tipper was very different from the present one (counting items vs. letter identification), so it is difficult to determine why the two paradigms yield different results. One possibility is that the probe displays in Driver and Tipper always contained target and distractor items in different colors, making probe selection relatively easy. Several experiments have shown that more difficult probe selection results in a larger magnitude of negative priming (e.g., Moore, 1994). In the present experiments, probe displays always contained target and distractor items in the same color, making selection relatively difficult. Under these conditions, grouping manipulations on the prime display may have been more salient than in the experiments of Driver and Tipper. Although the present results contrast with those of Driver and Tipper, they are consistent with previous findings that distractor items that are grouped with a target by means of spatial proximity lead to greater levels of negative priming (Fox, 1994, Experiment 1). In summary, the first two experiments suggest that distractor items that can be grouped with a target by means of common color produce more response competition and more negative priming than items that are perceptually segregated.

\section{EXPERIMENT 3}

The previous two experiments demonstrated that the amount of response competition and negative priming from irrelevant distractors is not solely a function of the distractor's distance from the target. Distractors that share the target's color produce more response competition and more negative priming than those that do not. This was true even when the target's color was randomized so that color could not be used as a selection cue (Experiment 2). The next question is whether the effects of color are strong enough to override the effects of spatial proximity. Baylis and Driver (1992, Experiment 2) found that far distractors $\left(1.2^{\circ}\right.$ from fixation) that shared the target's color produced more response competition than did near distractors $\left(.6^{\circ}\right.$ from fixation) that were presented in a different color. The finding that grouping by means of common color (Baylis \& Driver, 1992) or common motion (Driver \& Baylis, 1989) can override the effects of distance is problematic for space-based models of visual attention and suggests that visual attention can be di- rected to perceptual groups in the environment as well as to unparsed spatial locations.

Two experiments were conducted to further investigate whether grouping by means of target-distractor color can override the effects of spatial proximity for both response competition and negative priming measures. The aim of Experiment $3 \mathrm{~A}$ was to establish that near distractors produce more response competition and negative priming than far distractors in the present paradigm. Thus, centrally located targets were presented simultaneously with either near $\left(1.2^{\circ}\right)$ or far $\left(2.4^{\circ}\right)$ distractors. Targets and distractors were always presented in the same color (either red or blue). Under these conditions, it was expected that near distractors would produce more response competition (Baylis \& Driver, 1992; Experiment 3; B. A. Eriksen \& C. W. Eriksen, 1974) as well as more negative priming (Fox, 1994, Experiment 1) than far distractors. The aim of Experiment 3B was to provide a further test of the hypothesis that far distractors presented in the same color as the target would produce more response competition and negative priming than near distractors presented in a different color. The only difference between Experiments 3A and 3B was that all stimuli on prime trials were presented in the same color (either red or blue) in Experiment 3A, whereas in Experiment 3B, near distractors were always presented in a different color from that of the target, and far distractors were always presented in the same color as the target (either red or blue).

\section{EXPERIMENT 3A}

\section{Method}

Subjects. Fifteen students ( 6 male, 9 female) at the University of Essex participated in the experiment. Subjects were between 17 and 35 years of age and reported normal or corrected-to-normal vision. Each subject was paid $£ 3.00$ to take part in a 40 -min experimental session.

Apparatus and Stimuli. Stimulus presentation and data collection were identical to those in Experiment 2 except that the uppercase letters S, X, I, and O were used as stimuli, each subtending about $.69^{\circ}$ of vertical and $.46^{\circ}$ of horizontal visual angle at a viewing distance of $46 \mathrm{~cm}$. The letters were presented in either red (MEL color code 4 ) or blue (MEL color code 1) with a center-to-center distance between fixation and near distractors of $1.2^{\circ}$, and a centerto-center distance between fixation and far distractors of $2.4^{\circ}$ of visual angle. Displays were viewed through a custom-built viewer that kept the eyes at a constant distance from the screen.

Design. The target and distractors on the prime display were always presented in the same color (red or blue). On the probe display, the target and distractors were always near (i.e., $1.2^{\circ}$ separation) and the target (and distractor) color was always the same as the target color of the immediately preceding prime display. Thus a red prime target was always followed by a red probe target and a blue probe target was always followed by a blue probe target. The withinsubjects factors were target-distractor separation (near vs. far) and response competition (congruent vs. incongruent) on the prime display and negative priming (C vs. IR) on the probe display. This design resulted in four conditions in the prime display: (1) Near congruentitems in the positions immediately adjacent to the target had the same identity as the target (e.g., OOO). No items occupied the far 
locations. (2) Far congruent-items in the far positions had the same identity as the target; locations close to the target were empty (e.g., $\mathrm{O} O \mathrm{O})$. (3) Near incongruent-items in the positions immediately adjacent to the target were associated with a different response to the target (e.g., IXI). (4) Far incongruent-items in the far positions were associated with a different response to the target (e.g., S O S).

Only probe displays following incongruent prime displays were analyzed. There were four conditions of interest on the probe displays. Note that "near" and "far" refer to the target-distractor distance on the prime display. All of the distractors on the probe display were adjacent to the target (i.e., $1.2^{\circ}$ from fixation) and always had a different identity from that of the target: (1) Near control-items close to the target were incongruent with the target; the far positions were empty. There was no overlap in letter identities between prime and probe displays (e.g., OXO followed by ISI). (2) Far control-this condition was identical to the previous one except that these probe displays followed far prime displays. There was no overlap in letter identities between prime and probe displays (e.g., O X O followed by ISI). (3) Near ignored repetition-items close to the target were incongruent; the far positions were empty. The target had the same identity as the near distractor on the immediately preceding prime display (e.g., IOI followed by SIS). (4) Far ignored repetition-the target had the same identity as the far distractor on the immediately preceding prime display (e.g., I O I followed by SIS).

Procedure. Subjects were informed that they would be dealing with four letters- $-\mathrm{S}, \mathrm{X}, \mathrm{I}$, and $\mathrm{O}$. These letters were printed in black tape on the $1,2,9$, and 0 keys at the top of a standard computer keyboard, respectively. Subjects used the index and middle fingers of each hand to make their responses and were encouraged to respond to the central letter as quickly as possible by pressing the appropriate key, while trying not to make mistakes. A trial was considered correct only if both the prime and the probe displays received correct responses. The sequence of events for each trial was as follows: (1) A fixation cross was presented in the center of the screen for $500 \mathrm{msec} ;(2)$ the prime display (consisting of a row of three letters) was presented for $200 \mathrm{msec}$. Subjects responded to the target letter by pressing the appropriate key. If they made a mistake, the computer emitted a $500-\mathrm{Hz}$ beep. (3) A blank screen was presented for $350 \mathrm{msec}$ following the subject's response to the prime display. (4) The probe display (consisting of a row of three letters) was presented for $200 \mathrm{msec}$. Subjects responded to the target letter by pressing the appropriate key. As in the prime display, the computer emitted a beep if an error was made. (5) There was an intertrial interval of $1,000 \mathrm{msec}$.

Each subject underwent a practice block of 30 trials followed by five blocks each consisting of 96 trials. Subjects could take short breaks if required between the experimental blocks. There were 240 congruent (120 near, 120 far) and 240 incongruent (120 near, 120 far) prime displays. Of the 240 probe displays following incongruent prime displays, 60 each were near control, far control, near ignored repetition, and far ignored repetition. Half of all trials were presented in red and half in blue; these were equally distributed across the different experimental conditions.

\section{Results}

Prime data. Trials containing errors or with RTs less than 100 or greater than $1,500 \mathrm{msec}$ on the prime display were excluded from the data set. Preliminary analysis revealed that target color (red or blue) did not exert a significant main effect and was not involved in any higher order interactions. Thus, subsequent analysis was on data collapsed over the two target colors. The means of the median correct RTs for the prime display are presented in Figure 5. These RTs were analyzed by means of a 2 (target-distractor separation: near vs. far) $\times 2$ (response

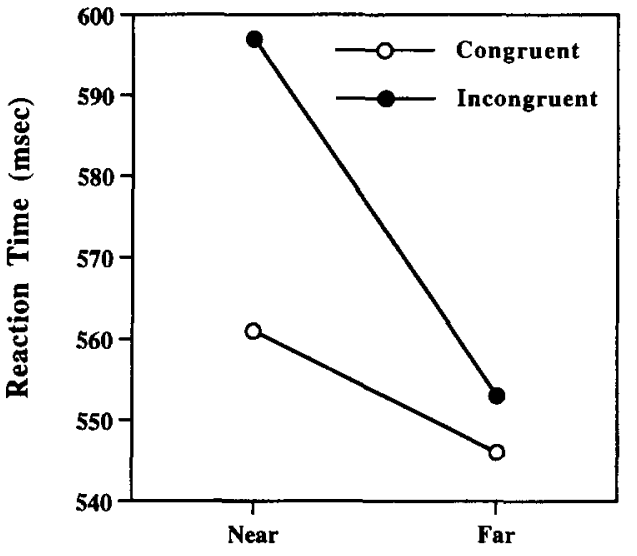

Target-Distractor Separation

Figure 5. Means of median correct reaction times for prime displays in Experiment 3A.

competition: congruent vs. incongruent) ANOVA with subjects as a random factor. This analysis revealed significant main effects of target-distractor separation $[F(1,14)$ $=16.8, M S_{\mathrm{e}}=767.2, p<.001$; faster RTs on far trials] and for response competition $\left[F(1,14)=27.5, M S_{\mathrm{e}}=\right.$ $262.2, p<.001$; faster RTs on congruent trials]. Of more interest, the target-distractor separation $\times$ response competition interaction was also significant $[F(1,14)=9.4$, $\left.M S_{\mathrm{e}}=331.9, p<.01\right]$. Further analysis by means of paired $t$ tests revealed that the magnitude of response competition was significant in the near condition [ $36 \mathrm{msec}: t(14)=$ $-4.68, p<.001]$ and approached significance in the far condition [7 msec: $t(14)=-1.71, p<.06]$.

The mean error rates for each condition are shown in Table 2 (Experiment 3A). The arcsin transformed error rates were subjected to the same analysis as the RT data. The only effect to reach significance was the main effect of response competition $\left[F(1,14)=4.9, M S_{\mathrm{e}}=.007\right.$, $p<.05]$.

Probe data. Trials with errors on either the prime display or the probe display were excluded from the data analysis, as were trials with RTs less than 100 or greater than 1,500 msec. The median correct RTs for the $\mathrm{C}$ and IR probe displays for both near and far conditions are presented in Figure 6 . The median correct RTs on probe trials were subjected to a 2 (target-distractor separation: near vs. far) $\times 2$ (negative priming: $C$ vs. IR) ANOVA with subjects as a random factor. There were significant main effects for both target-distractor separation (on the prime trial) $\left[F(1,14)=6.5, M S_{\mathrm{e}}=702.5, p<.05\right.$; faster RTs on probe displays following far prime displays] and negative priming $\left[F(1,14)=5.9, M S_{\mathrm{e}}=476.4, p<.05\right.$; slower RTs on IR than on C trials]. However, the targetdistractor separation $\times$ negative priming interaction was also significant $\left[F(1,14)=4.4, M S_{\mathrm{e}}=247.4, p<.054\right]$. Further analysis revealed that there was reliable negative priming in the near condition [ $22 \mathrm{msec}: t(14)=-2.52$, 
Table 2

Mean Error Rates on Prime and Probe Displays in Experiments $3 \mathrm{~A}$ and $3 \mathrm{~B}$

\begin{tabular}{lcc}
\hline \multicolumn{1}{c}{ Display } & \multicolumn{2}{c}{ Prime Target-Distractor Separation } \\
\cline { 2 - 3 } & Near & Far \\
\hline Prime & .03 & \\
$\quad$ Congruent & .05 & .02 \\
$\quad$ Incongruent & & .03 \\
Probe & .04 & \\
$\quad$ Control & .06 & .04 \\
Ignored repetition & .05 \\
& Experiment 3B & \\
Prime & & \\
Congruent & .04 & .04 \\
$\quad$ Incongruent & .04 & .05 \\
Probe & & .02 \\
$\quad$ Control & .03 & .04 \\
Ignored repetition & & \\
\hline
\end{tabular}

$p<.012$ ] but not in the far condition [ $5 \mathrm{msec}: t(14)=$ $-1.2, p<.12]$.

The mean error rates on the probe display are presented in Table 2 (Experiment 3A). The ANOVA showed no significant main effects or interactions.

\section{EXPERIMENT 3B}

The design of Experiment 3B was the same as that of Experiment $3 \mathrm{~A}$ except that the far distractors were always presented in the same color as the target (red or blue) and the near distractors were always presented in the other color, with target color being randomized from trial to trial. Under these conditions, it was expected that far distractors would produce more response competition and negative priming than near distractors. As in Experiment 2, the random variation of target color from trial to trial prevented subjects from being able to use target color as an additional selection cue. Fifteen new subjects ( 5 male, 10 female) between 20 and 32 years of age took part in this experiment.

\section{Results}

Prime data. Trials containing errors or with RTs less than 100 or greater than $1,500 \mathrm{msec}$ on the prime display were excluded from the data set. Preliminary analysis revealed that target color (red or blue) did not exert a significant main effect and was not involved in any higher order interactions. Thus, subsequent analysis was on data collapsed over the two target colors. The means of the median correct RTs for the prime display are presented in Figure 7 . These RTs were analyzed by means of a 2 (target-distractor separation: near vs. far) $\times 2$ (response competition: congruent vs. incongruent) ANOVA with subjects as a random factor. The main effect for response competition was significant $[F(1,14)=12.8$, $\left.M S_{\mathrm{e}}=530.2, p<.01\right]$. In contrast to the results of Ex- periment $3 \mathrm{~A}$ there was no target-distractor separation $\times$ response competition interaction $[F(1,14)<1]$.

The mean error rates are presented in Table 2 (Experiment 3B). The arcsin transformations of these error rates were subjected to the same analysis as the RT data. This analysis revealed no main effects or interactions.

Probe data. Trials with errors on either the prime display or the probe display were excluded from the data analysis, as were trials with RTs less than 100 or greater than $1,500 \mathrm{msec}$. The median correct RTs for the $\mathrm{C}$ and IR probe displays for both near and far conditions are presented in Figure 8. The median correct RTs on probe trials were subjected to a 2 (target-distractor separation: near vs. far) $\times 2$ (negative priming: $C$ vs. IR) ANOVA with subjects as a random factor. There was a significant main effect for target-distractor separation (on the prime trial) $\left[F(1,14)=19.5, M S_{\mathrm{e}}=73.0, p<.001\right.$; slower RTs on probe displays following far prime displays], whereas the main effect of negative priming approached significance $\left[F(1,14)=4.0, M S_{\mathrm{e}}=361.2, p<.06\right.$; slower RTs on IR relative to $C$ trials]. Of more interest, however, the target-distractor separation $\times$ negative priming interaction was significant $\left[F(1,14)=26.4, M S_{\mathrm{e}}=67.8, p<\right.$ $.001]$. Further analysis revealed that negative priming occurred in the far (i.e., same color) condition $[21 \mathrm{msec}$ : $t(14)=-3.2, p<.01]$ but not in the near (i.e., differentcolor) condition $[t(14)<1]$.

The mean error rates are presented in Table 2 (Experiment 3B). The arcsin transformations of these error rates were subjected to the same analysis as the RT data. This analysis revealed no significant main effects or interactions.

\section{Discussion of Experiments $3 A$ and $3 B$}

The results of Experiment 3A demonstrated that when target and flanking distractors were presented in the same color, spatial proximity exerted a strong influence on both

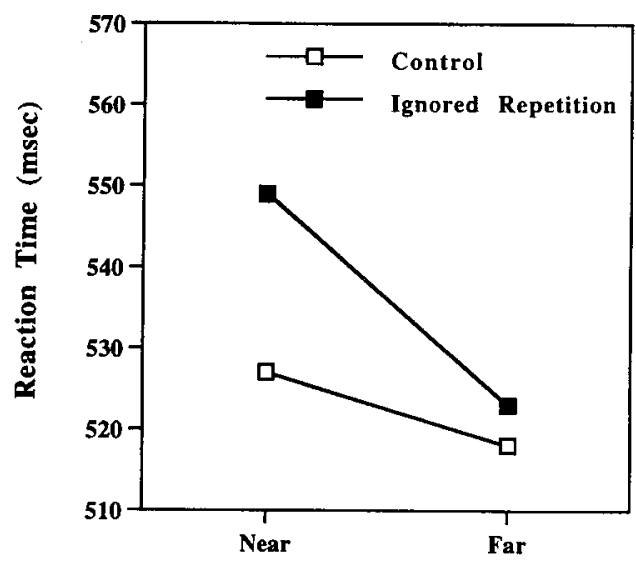

Target-Distractor Separation

Figure 6. Means of median correct reaction times for probe displays in Experiment 3A. 


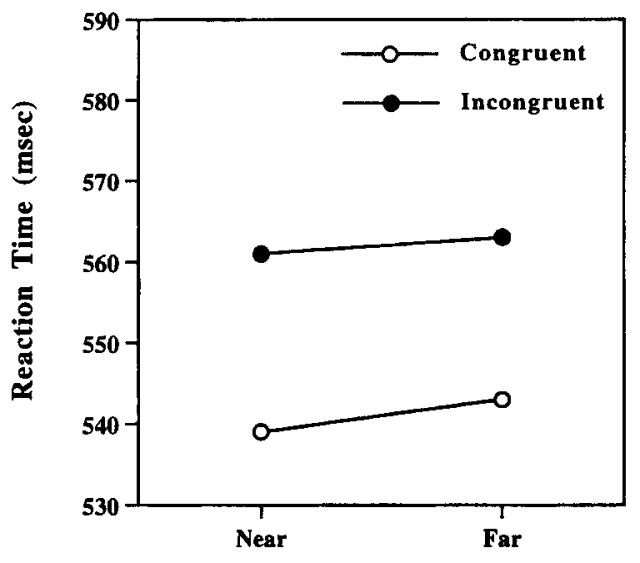

Target-Distractor Separation

Figure 7. Means of median correct reaction times for prime displays in Experiment 3B.

response competition and negative priming. Distractors that were presented near the centrally located target produced more response competition and more negative priming than distractors that were presented farther away from the target. These results replicate those reported by Fox (1994, Experiment 1) and cannot distinguish between space- and object-based accounts of visual attention. However, the results of Experiment 3B are more suggestive of object-based selection. The only difference in this experiment was that near distractors were presented in a different color from that of the target while far distractors were presented in the same color. Under these conditions, there was no interaction between spatial proximity and response competition. This difference between the two experiments was confirmed by a 2 (experiment: $3 \mathrm{~A}$ vs. 3B) $\times 2$ (target-distractor separation: near vs. far) $\times 2$ (response competition: congruent vs. incongruent) interaction $\left[F(1,28)=5.8, M S_{\mathrm{e}}=245.6, p<.022\right]$. Thus the typical interaction between spatial proximity and response competition (Experiment 3A) was eliminated when the far distractors (but not the near distractors) could be grouped with the target by means of common color (Experiment 3B).

The results from the probe displays indicate that grouping by means of common color can sometimes override the effects of spatial proximity. When prime targets and distractors were presented in the same color (Experiment $3 \mathrm{~A}$ ) substantially greater negative priming was observed from near distractors than from far distractors ( -22 vs. $-5 \mathrm{msec}$, respectively), replicating previous results (Fox, 1994). However, when the far prime distractors were presented in the same color as the target but the near prime distractors were presented in a different color (Experiment 3B), this pattern was reversed: Less negative priming was observed from near distractors than from far distractors $(+2 \mathrm{vs}$. $-21 \mathrm{msec}$, respectively). This difference between the experiments was confirmed by a significant 2 (experiment: $3 \mathrm{~A}$ vs. $3 \mathrm{~B}) \times 2$ (target - distractor separation: near vs. far) $\times 2$ (negative priming: C vs. IR) interaction $\left[F(1,28)=18.0, M S_{\mathrm{e}}=157.6\right.$, $p<.001]$.

A problem in interpreting the results of Experiments $3 \mathrm{~A}$ and $3 \mathrm{~B}$, however, is that the three-way interactions among experiment, target-distractor separation, response competition, and negative priming, respectively, seem to be driven as much by a dissociation in the far condition effects as to a dissociation in the near condition effects. Remember that the far conditions were designed to be exactly identical across the two experiments and yet the magnitude of both response competition ( +9 and $+22 \mathrm{msec}$ ) and negative priming $(-4$ and $-21 \mathrm{msec})$ effects were quite different between Experiments $3 \mathrm{~A}$ and $3 \mathrm{~B}$, respectively. Because of this pattern, it is difficult to attribute all of the effects solely to the grouping parameters of items in the prime display. Rather, it seems that there might be some powerful experiment-wide contextual effects that may be playing an important role here. For example, within each experiment there may be something like a contrast effect (relatively easy primes vs. relatively difficult primes) to which the attention system is reactive. In Experiment $3 \mathrm{~A}$, in which the within-display colors were all the same, the far distractors may have been easier to deal with than the near distractors. In Experiment 3B, however, the distinguishing color of the near distractors may have made them easier to deal with than the far distractors that shared the same color as the target.' Similarly, it is possible that when all of the items are presented in the same color (Experiment $3 \mathrm{~A}$ ), spatial proximity is especially salient and exerts a strong effect on attentional mechanisms. However, when some trials contain different-color distractors (Experiment 3B), spatial proximity is less salient and therefore does not exert such a strong affect on attentional mechanisms. This would explain the different pattern of effects on the "identical" far trials across the two experiments. These experiment-wide contextual factors make it difficult to conclude conclusively

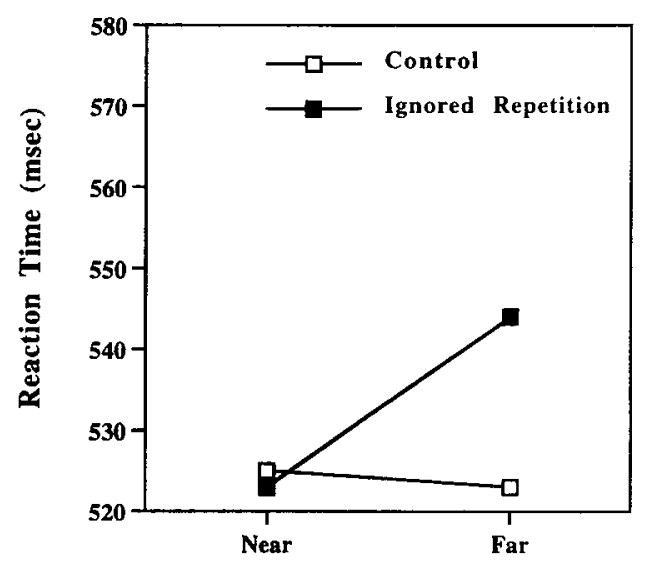

Target-Distractor Separation

Figure 8. Means of median correct reaction times for probe displays in Experiment 3B. 
that perceptual grouping on the prime display was the main determinant of the observed pattern of results.

There is a potentially more serious problem in interpreting the negative priming results of all of the experiments reported so far. In all cases, perceptual grouping (same vs. different color) on the prime display was completely confounded with the similarity between the prime distractor and the probe target. For example, in the samecolor prime displays in all experiments, the subsequent probe target (and distractors) was always presented in the same color as the prime target. Therefore, increased negative priming in the same-color condition may have been due to the greater similarity between prime distractors and probe targets in the same-color relative to the differentcolor prime displays. Two recent studies support this possibility by showing that when prime and probe displays are matched in terms of target-distractor onsets (Neill, 1997) or contrast intensities (Fox \& de Fockert, 1998), greater negative priming is produced than when prime and probe displays are mismatched. It should be noted, however, that Fox and de Fockert (unpublished data) failed to find evidence that color matching across prime and probe displays influenced negative priming. Nevertheless, since a primary aim of the present study was to determine whether perceptual grouping on the prime display can override the potent spatial proximity factors in negative priming, it was considered important to unconfound grouping on the prime display and prime distractor-probe target similarity. This was the aim of Experiment 4.

\section{EXPERIMENT 4}

All of the preceding experiments reported in this paper used grouping by means of color on the prime display. As noted, a problem with this approach (at least for the negative priming measure) is that there is a greater similarity between prime and probe displays on same-color trials than on different-color trials, and this may have produced the pattern of negative priming results. Experiment 4 unconfounds these two factors by presenting a letter identification task, as before, but this time target and distractor letters were presented on either the same object or on different objects in prime displays. Previous research has shown that a greater magnitude of response competition occurs when distractors form part of the same object as a target than when the distractors form part of a different object from the target (Kramer \& Jacobson, 1991). The aims of Experiment 4 were to replicate this finding and to test whether perceptual grouping on the prime display influences the magnitude of negative priming observed. The advantage of the same-different object manipulation for the latter purpose is that the degree of similarity between prime and probe displays can be equated for the same- and different-object prime displays. Indeed, if anything, the similarity between the different-object prime display and the subsequent probe display is greater than the similarity between the same- object prime display and the probe display in this experiment (see Figure 9). There were four critical prime conditions in this experiment: far different object, near different object, far same object, and near same object. A strong version of location-based selection would predict stronger effects (for both response competition and negative priming) when prime distractors are near to the target than when they are far, regardless of which object the target and distractors appear on (same or different). In contrast, object-based selection would predict stronger effects when prime distractors appear on the same object as the target. Furthermore, since spatial proximity also forms a strong grouping factor, this account would also predict stronger effects from near than from far distractors. Thus, the critical comparisons for the two hypotheses are as follows. First, the location-based account would predict less response competition and negative priming from far-same-object distractors than from near-differentobject distractors. The object-based account would predict either no difference between these two conditions or stronger effects on the far-same-object condition. Second, the location-based account would predict an equivalent magnitude of effects across the far-same-object and the far-different-object conditions. In contrast, the objectbased account predicts stronger effects in the far-sameobject condition than in the far-different-object condition. These predictions were tested in Experiment 4.

\section{Method}

Subjects. Twenty-two students at the University of Essex participated in the experiment. Subjects were between 19 and 28 years of age and reported normal or corrected-to-normal vision. Each subject took part in a single experimental session lasting about $40 \mathrm{~min}$, for which they were paid $£ 2.00$.

Apparatus and Stimuli. Stimulus presentation and data collection were identical to those of Experiment 3 except that target and distractor stimuli were the capital letters A, B, C, or D, each subtending about $.27^{\circ}$ of vertical and $.16^{\circ}$ of horizontal visual angle at a viewing distance of $105 \mathrm{~cm}$. Subjects responded to the centrally located letter by pressing the 1,2, 9, or 0 key. Each letter was presented inside a circle with a radius of about $.38^{\circ}$ of visual angle (see Figure 9 for stimuli). All letters and circles were presented in white against a black background. The prime target letter always appeared in the central circle and distracting letters appeared in circles that were placed to the left and right at an edge-to-edge separation of either $.55^{\circ}$ of visual angle (near) or $.93^{\circ}$ of visual angle (far). This gave a letter-to-letter separation of about $.87^{\circ}$ and $1.3^{\circ}$ of visual angle for the near and far prime conditions, respectively. Probe target letters always appeared at the center of the screen inside a circle with a radius of $38^{\circ}$, and distracting letters appeared inside circles to the left and right that had an edge-to-edge separation of $71^{\circ}$ on the probe displays. This resulted in a letter-to-letter separation of about $1.0^{\circ}$ of visual angle. The horizontal visual angle of the entire display was $2.3^{\circ}$ and $3.1^{\circ}$ for near and far prime conditions, and $2.6^{\circ}$ for the probe display. On half of the prime displays, the three circles were connected by two horizontal lines connecting the left and right circles to the central circle (same-object condition). For the other half of trials, the three circles were not connected to each other (differentobject condition).

Design and Procedure. The experimental design was completely within subjects. The factor of object related only to the prime display. On half of the trials, the circles containing target and dis- 
Far Different Object

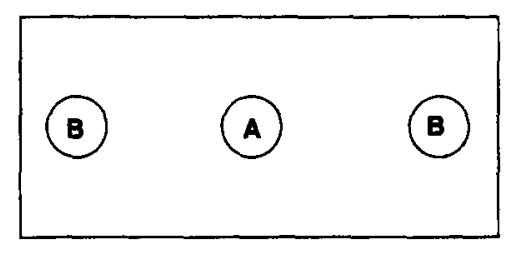

Near Different Objecrt

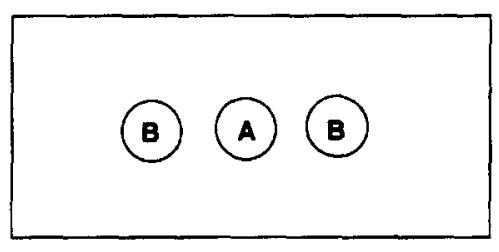

Far Same Object
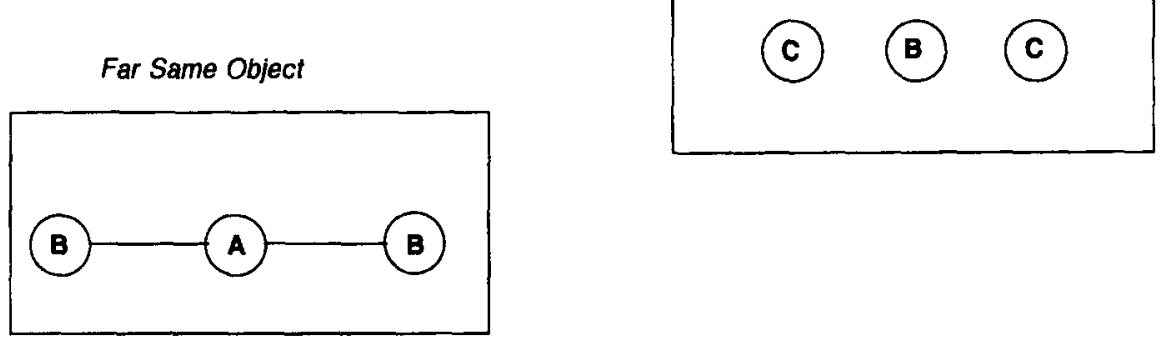

Near Same Object

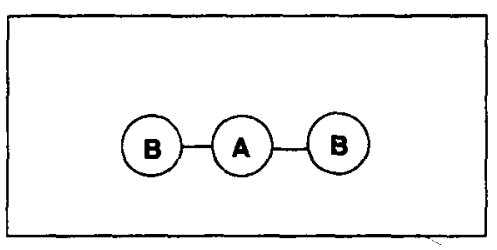

Prime Diaplay

Probe Display

Figure 9. An illustration of the stimuli used in Experiment 4. In the same-object conditions, the two flanking circles on the prime display were connected to the central (target) circle by means of a horizontal line. In the different-object conditions, the flanking circles and the target circles were not connected. The target and distractor letters appeared inside these circles. On probe displays, target and distractor letters were presented within circles. The example shown represents an ignored repetition trial.

tractor letters were connected by means of a horizontal line (see Figure 9; same object), whereas in half of the trials, the central and flanking circles were not connected (different object). Target distractor separation was manipulated only on prime displays, with distracting letters appearing either near $\left(.87^{\circ}\right)$ or far $\left(1.3^{\circ}\right)$ from the central target letter. The other two factors were response competition (congruent vs. incongruent prime displays) and negative priming ( $C$ vs. IR probe displays). All of these within-subjects factors were completely randomized. Each subject completed seven blocks of 48 trials (a trial consisted of a prime and a probe display). The first block of trials was considered practice, so subjects completed 336 experimental trials in total. There were 144 congruent prime displays, with half of these being same-object trials (i.e., target and distractor circles were connected) and half being different-object trials (i.e., target and distractor circles unconnected). Half of each of these conditions had near distracting target letters and half had far distracting target letters. The breakdown was similar for the 144 incongruent prime displays. The 144 probe displays following congruent prime displays were not included in the analysis. Of the 144 probe displays following incongruent prime displays, 72 were $\mathrm{C}$ and 72 were IR. Half of all the $C$ probe displays followed sameobject prime displays ( 18 following near prime distractors, 18 following far prime targets) and half followed different-object prime displays ( 18 following near prime distractors, 18 following far prime distractors). The breakdown was the same for the IR trials.

The sequence of events within each trial was as follows: A fixation point $(+)$ was presented at the center of the computer screen for $500 \mathrm{msec}$. This display was replaced by the prime display, which 


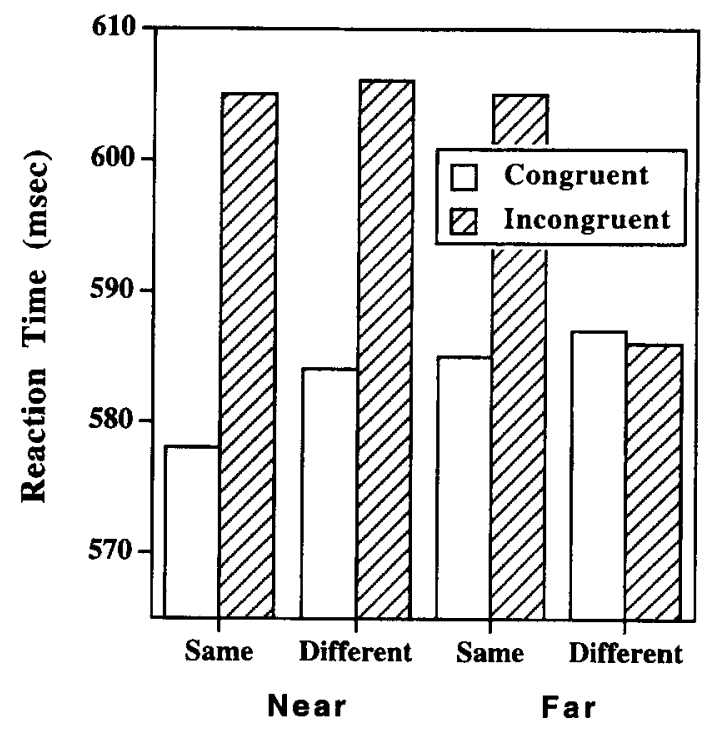

Figure 10. Means of median correct reaction times for prime displays in Experiment 4.

was presented for $300 \mathrm{msec}$. This was followed by a blank screen until a response was made or until 2,000 msec had elapsed. Following the response (or after 2,000 msec), there was a blank screen for $300 \mathrm{msec}$, and then the probe display was presented in the same location for $300 \mathrm{msec}$. A blank screen was presented until a response was made or until $2,000 \mathrm{msec}$ had elapsed. There was an intertrial interval of $800 \mathrm{msec}$.

\section{Results}

Prime data. Trials containing errors or with RTs less than 100 or greater than $1,500 \mathrm{msec}$ on the prime display were excluded from the data set. The means of the median correct RTs for the prime display are presented in Figure 10 . These RTs were analyzed by means of a 2 (object: same vs. different) $\times 2$ (target-distractor separation: near vs. far) $\times 2$ (response competition: congruent vs. incongruent) ANOVA with subjects as a random factor. The only main effect to reach significance was response competition $\left[F(1,21)=7.9, M S_{\mathrm{e}}=1,592.16, p<.01\right]$. Of more importance, there was a significant response competition $\times$ target-distractor separation interaction $\left[F(1,21)=9.3, M S_{\mathrm{e}}=279.7, p<.006\right]$. Planned comparisons revealed that near distractors produced more response competition ( $25 \mathrm{msec}$ ) than far distractors $(9 \mathrm{msec})$ $[t(21)=3.04, p<.001]$. The response competition $\times$ object interaction approached significance $[F(1,21)=$ $\left.3.69, M S_{\mathrm{e}}=474.51, p<.068\right]$. Planned comparisons revealed that distractors on the same object as the target produced more response competition $(23 \mathrm{msec})$ than distractors on different objects $(11 \mathrm{msec})[t(21)=1.92, p<$ $.035]$. Planned comparisons were also conducted on the two critical comparisons outlined in the introduction. There was no difference in the magnitude of response competition between the far-same-object and near-differentobject conditions [20 vs. $22 \mathrm{msec}$, respectively; $t(21)<$ 1]. However, greater response competition was observed in the far-same-object condition than in the far-differentobject condition [ $20 \mathrm{vs}$. $-1.1 \mathrm{msec}, t(21)=1.99, p<.03$ ]

The mean error rates are presented in Table 3 . The arcsin transformations of these error rates were subjected to the same analysis as the RT data. The only effect to reach significance was a main effect of response competition $\left[F(1,21)=6.2, M S_{\mathrm{e}}=0.111, p<.021\right]$; more errors were made on incongruent (.063) than on congruent (.035) displays].

Probe data. Trials with errors on either the prime display or the probe display were excluded from the data analysis, as were trials with RTs less than 100 or greater than 1,500 msec. The median correct RTs for the C and IR probe displays as a function of same- or different-object and near and far conditions on the prime display are presented in Figure 11. The median correct RTs on probe trials were subjected to a 2 (object: same vs. different) $\times$ 2 (target-distractor separation: near vs. far) $\times 2$ (negative priming: $\mathrm{C}$ vs. IR) ANOVA with subjects as a random factor. This analysis revealed a significant main effect of negative priming $\left[F(1,21)=5.84, M S_{\mathrm{e}}=809.5\right.$, $p<.025]$. The only other significant effect was a negative priming $\times$ object interaction $\left[F(1,21)=6.44, M S_{\mathrm{e}}=\right.$ $965.63, p<.019]$. Planned comparisons revealed that negative priming was greater in the same-object $(-22 \mathrm{msec})$ than in the different-object $(+1.5 \mathrm{msec})$ condition $[t(21)=$ $2.54, p<.001]$. The target-distractor separation $\times$ negative priming interaction was not significant $[F(1,21)=$ $\left.1.8, M S_{\mathrm{e}}=716.3, p<.18\right]$. However, there was a tendency for an object $\times$ target-distractor separation $\times$ negative priming interaction $\left[F(1,21)=3.73, M S_{\mathrm{e}}=495.3, p<\right.$ .067]. Further analysis revealed a different pattern of results for the near and far conditions. For the near spatial separation, there was a strong negative priming effect $\left[F(1,21)=8.33, M S_{\mathrm{e}}=860.6, p<.009\right]$, with reliable negative priming occurring for both the same object $[-23$ msec: $t(21)=2.54, p<.01]$ and the different-object [ -13 msec: $t(21)=1.75, p<.047]$ conditions. However, for the far spatial separation there was an interaction between object and negative priming $[F(1,21)=9.14$, $\left.M S_{\mathrm{e}}=811.89, p<.006\right]$. Further analysis revealed significant negative priming $(-21 \mathrm{msec})$ for the same-object condition $[t(21)=2.39, p<.013]$. No negative priming was observed in the different-object condition, and in fact a trend toward positive priming $(+16 \mathrm{msec})$ was observed $[t(21)=1.77, p<.092$ (two-tailed) $]$. Planned comparisons

Table 3

Mean Error Rates on Prime and Probe Displays in Experiment 4

\begin{tabular}{lcccc}
\hline \multicolumn{5}{c}{ in Experiment 4 } \\
\cline { 2 - 5 } Display & $\begin{array}{c}\text { Near Same } \\
\text { Object }\end{array}$ & $\begin{array}{c}\text { Near Different } \\
\text { Object }\end{array}$ & $\begin{array}{c}\text { Far Same } \\
\text { Object }\end{array}$ & $\begin{array}{c}\text { Far Different } \\
\text { Object }\end{array}$ \\
\hline Prime & & & & \\
Congruent & .05 & .03 & .03 & .03 \\
Incongruent & .06 & .06 & .04 & .09 \\
Probe & & & & \\
Control & .04 & .04 & .05 & .05 \\
IR & .04 & .05 & .05 & .04 \\
\hline
\end{tabular}




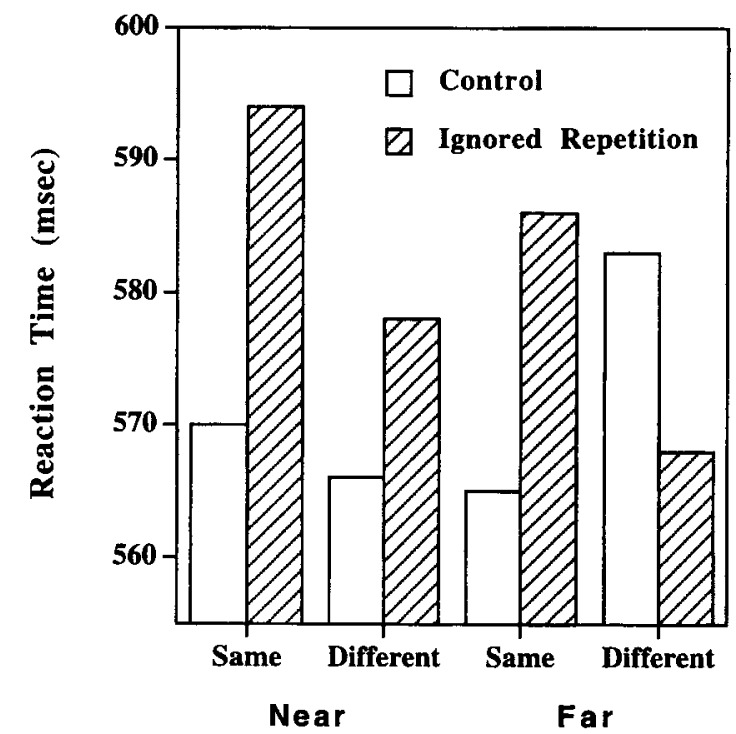

Figure 11. Means of median correct reaction times for probe displays in Experiment 4.

revealed no difference in the magnitude of negative priming between the far-same-object and the near-differentobject conditions [ -21 and $-13 \mathrm{msec}$, respectively: $t(21)<$ 1]. In contrast, the far-same-object condition produced more negative priming than the far-different-object condition $[-21$ vs. +16 msec: $t(21)=3.02, p<.001]$.

The mean error rates are presented in Table 3 . The arcsin transformations of these error rates were subjected to the same analysis as the RT data. There were no significant main effects or interactions.

\section{Discussion}

The results from this experiment do not support a strong version of location-based selection. In contrast, the results are compatible with object-based selection. On the prime display, there was evidence that spatial proximity as well as whether a distractor appears on the same object as or a different object from a target is an important determinant of response competition (see also Kramer \& Jacobson, 1991). The critical result was that distractors at a far spatial separation could produce as much response competition as near distractors as long as they were presented on the same object as the target.

A major aim of this experiment was to determine whether the impact of perceptual grouping by means of same or different objects would also influence the inhibitory mechanisms of visual selective attention. Clear evidence for inhibition of object-based representations was found. When distracting letters were presented on the same object as the target letter on a prime display, those distractors produced a greater magnitude of negative priming on the subsequent probe display than when the prime distractors appeared on a different object. Remember that the present paradigm unconfounds the greater similarity between prime distractors and probe targets on "grouped" (i.e., same-object) versus ungrouped (i.e., different-object) prime displays that was a feature of the color experiments (Experiments 1 to 3B). Thus, the present results provide clearer evidence that prime display grouping factors can have a strong impact on subsequent negative priming. There was a marginally significant interaction between same or different object, near or far spatial separation, and the negative priming measure. This was driven primarily by a tendency for facilitation rather than inhibition in the far-differentobject condition. In all other conditions, reliable negative priming was found. The important result was that the magnitude of negative priming from distractors that were at the far spatial separation on the prime display produced as much negative priming as near distractors if they were presented on the same object as the target on the prime display.

\section{GENERAL DISCUSSION}

The present study set one grouping factor (targetdistractor color; same-different object) against another (target-distractor proximity) to determine whether grouping by means of common color (Experiments 1-3B) or object (Experiment 4) can produce similar effects on grouping by means of spatial location in a selective attention task. The concurrent interference produced by a distractor that is presented at the same time as the target was measured by means of response competition (see, e.g., B. A. Eriksen \& C. W. Eriksen, 1974), whereas the subsequent influence of the ignored item on target selection was measured by means of negative priming (see, e.g., Tipper, 1985). The results clearly demonstrate that the amount of response competition and negative priming from distractors is not determined solely by targetdistractor proximity. Rather, the formation of a perceptual group between target and distractor items, or the presentation of a distractor on the same object as the target, is also an important determinant of interference and priming effects.

These results are difficult to reconcile with a strict spotlight model of attention and add to the growing evidence that visual attention can be directed to segmented perceptual groups in a visual scene rather than only to unsegmented regions of visual space (e.g., Driver, 1995; Kanwisher \& Driver, 1992; van der Heijden et al., 1996). The present study demonstrates that proximal items tend to be grouped together when there is no other obvious way to group objects in a visual scene. However, when there is another salient way to group items besides spatial location (such as common color or object), attention can be directed to these perceptual groups and the influence of spatial proximity is attenuated. It seems clear that spatial location does not play a unique role in directing visual attention. Rather, spatially proximal items provide an important grouping cue that is efficient in directing visual attention to particular locations in visual space. 
However, other grouping factors (in this case common color or same vs. different objects) can have very similar effects in directing visual attention. Thus, visual attention can select either locations or objects, depending on the parameters of a particular scene.

Lavie and Driver (1996) have recently suggested, however, that object-based effects may operate only within an attended spatial region. In the present study, target and distracting items always appeared in expected locations (either near or far), and therefore subjects may have adopted a diffuse spatial setting of attention prior to display onset since distractors were equally likely to appear in near and far locations. Such a strategy is compatible with the notion that object-based effects may occur only within an expected region and indicates that visual selection may operate within a "grouped spatial array" (Kramer \& Jacobson, 1991; Kramer, Weber, \& Watson, 1997; Lavie \& Driver, 1996; Vecera \& Farah, 1994; but see Vecera, 1997) that is subject to both location- and object-based influences. The implication of this is that visual attention selects from a grouped location-based representation so that selection ultimately takes place from a spatial medium (Kramer et al., 1997).

It should be noted, however, that in the present experiments the target item always appeared at fixation and therefore there was no strong incentive for subjects to adopt a diffuse spatial setting. In spite of this, object-based effects occurred even when the target appeared in a narrowly attended central region. Future studies could use the current paradigm but could present targets to the left and right of fixation in same- and different-object conditions. The interesting result would be whether objectbased effects on response competition and negative priming would occur even when the location of the target was precued (see Lavie \& Driver, 1996). As things stand, however, the present investigation suggests that focused attention is strongly influenced by objects that compete for selection, rather than distinct locations per se. There is also converging evidence for this view from neuropsychological studies showing that the spatial biases observed in unilateral neglect can be modulated by object segmentation and perceptual grouping factors (see Driver, 1995, for review). The precise nature of the representation from which object-based selection operates (e.g., grouped spatial arrays or spatially invariant arrays) is a question for future research (Kramer et al., 1997; Vecera, 1997).

The present study extends previous research on perceptual grouping and attentional selection to the negative priming paradigm. As mentioned in the introduction, the most widespread interpretation of the negative priming effect is that distracting items are actively suppressed in order to aid target selection and that this inhibition carries over to subsequent responding, producing a delay in responding if previously ignored items have to be responded to (e.g., Houghton \& Tipper, 1994; Neill, 1977; Tipper, 1985). On this view, it should be more difficult to ignore objects that are grouped with the target than items that do not form part of the same perceptual group.
Thus, more inhibition should be applied to distracting items that are perceptually grouped with that target. The present results are consistent with this hypothesis. However, the results can also be interpreted in terms of a recently proposed episodic retrieval theory of negative priming that does not rely on inhibitory processes (Neill \& Valdes, 1992; Neill, Valdes, Terry, \& Gorfein, 1992). The episodic retrieval hypothesis suggests that probe displays can act as retrieval cues that lead to the automatic retrieval of previously processed episodes. When a previously ignored item is retrieved and now must be selected, the mismatch between the object's previous (irrelevant) and current (relevant) status causes a delay in responding. A prediction of this memory-based account is that greater similarity between prime and probe displays should result in a greater magnitude of negative priming (see Fox \& de Fockert, 1998, Neill, 1997, for supporting evidence). Recall that in the present color experiments (Experiments 1-3B), all probe displays presented target and distractor items in the same color. Therefore, there was greater prime-probe similarity on same-color prime trials than on different-color prime trials. Consistent with the episodic retrieval hypothesis, more negative priming occurred on the same-color (similar) prime trials than on the different-color (dissimilar) prime trials. However, in Experiment 4, the confound between perceptual grouping on the prime display and the degree of prime-probe similarity was eliminated, and it was still shown that more negative priming occurred on grouped prime displays than on ungrouped prime displays. Therefore, perceptual grouping on a prime display is clearly an important determinant of visual selection as measured by both response competition and negative priming. The present study was not designed to distinguish between selective inhibition and episodic-retrieval-based accounts of negative priming, and the results can be interpreted from either perspective (see Fox, 1995a; Fox \& de Fockert, 1998; May et al., 1995; Neill, 1997; Neill \& Valdes, 1996; Tipper \& Milliken, 1996, for further discussion of retrieval- and inhibition-based accounts of negative priming).

A related issue concerns the nature of the relationship between measures of response competition and negative priming. Previous research has suggested that the two indices of distractor processing are independent of each other (Driver \& Tipper, 1989; Fox, 1994; Fox, 1995b). However, the present experiments as well as other recent work suggest a positive correlation between the two measures (e.g., Kramer, Humphrey, Larish, Logan, \& Strayer, 1994; Neill et al., 1995; Ruthruff \& Miller, 1995). The theoretical implications of a positive correlation between response competition and negative priming is difficult to assess given the complexity of the relationship between the two measures (see, e.g., Fox, 1995a; Tipper \& Milliken, 1996). In brief, a strong version of inhibition theory might predict an inverse relation since stronger inhibition (more negative priming) should result in less interference from competing distractors (less response com- 
petition). Alternatively, stronger interference from competing objects may induce stronger inhibition, so that a positive relation can also be explained by the notion of reactive inhibition. Finally, the episodic retrieval account would also predict a positive relation between the two measures since more extensive processing of a prime distractor should result in greater response competition and increase the likelihood that an inaction tag would be laid down (hence more negative priming). Thus, the positive relation between the two indices of distractor processing that seems to be the modal finding can be accounted for by both inhibition- and retrieval-based accounts of negative priming (see Fox, 1995a; Neill et al., 1995; Tipper \& Milliken, 1996, for further discussion).

To conclude, the present results indicate that distracting items that are perceptually grouped with a target item produce more negative priming (and response competition) than distractors that are easily segmented from the target. One caveat to note is that all of the present experiments featured a selective attention task of low perceptual load (i.e., a target and a maximum of two distractors). Previous research has shown that response competition occurs only under conditions of low perceptual load and disappears when perceptual load is high (Lavie, 1995). We have recently found that negative priming is also restricted to conditions of low perceptual load and does not occur when load is high (Lavie \& Fox, 1997). Whether strong grouping between target and distractor objects can lead to response competition and negative priming under conditions of high perceptual load remains a question for future research. At least for conditions of low perceptual load, the present results indicate that visual attention can be directed to segmented perceptual groups or objects in the visual environment and not just to unparsed spatial locations.

\section{REFERENCES}

BaYlis, G. C., \& Driver, J. (1992). Visual parsing and response competition: The effect of grouping factors. Perception \& Psychophysics, 51, 145-162.

BaYLIS, G. C., \& Driver, J. (1993). Visual attention and objects: Evidence for hierarchical coding of locations. Journal of Experimental Psychology: Human Perception \& Performance, 19, 451-470.

Dalry MPle-Alford, E. C., \& BudAYR, B. (1966). Examination of some aspects of the Stroop color-word test. Perceptual \& Motor Skills, 23, 1211-1214.

DrIVER, J. (1995). Object segmentation and visual neglect. Behavioural Brain Research, 71, 135-146.

DRIVER, J., \& BAYLIS, G. C. (1989). Movement and visual attention: The spotlight metaphor breaks down. Journal of Experimental Psychology: Human Perception \& Performance, 15, 448-456.

Driver, J., \& TIPPER, S. P. (1989). On the nonselectivity of selective seeing: Contrasts between interference and priming in selective attention. Journal of Experimental Psychology: Human Perception \& Performance, 15, 304-314.

DunCaN, J. (1984). Selective attention and the organization of visual information. Journal of Experimental Psychology: General, 113, 501-517.

Eriksen, B. A., \& Eriksen, C. W. (1974). Effects of noise letters upon the identification of a target letter in a nonsearch task. Perception \& Psychophysics, 16, 143-149.
ERIKSEN, C. W., \& ST. JAMES, J. D. (1986). Visual attention within and around the field of focal attention: A zoom lens model. Perception \& Psychophysics, 40, 225-240.

ERIKSEN, C. W., \& YEH, Y. Y. (1985). Allocation of attention in the visual field. Journal of Experimental Psychology: Human Perception \& Performance, 5, 583-597.

Fox, E. (1994). Interference and negative priming from ignored distractors: The role of selection difficulty. Perception \& Psychophysics, 56, 565-574.

Fox, E. (1995a). Negative priming from ignored distractors in visual selection: A review. Psychonomic Bulletin \& Review, 2, 145-173.

Fox, E. (1995b). Pre-cuing target location reduces interference but not negative priming from visual distractors. Quarterly Journal of Experimental Psychology, 48A, 26-40.

Fox, E., \& DE FOCKERT, J. W. (1998). Negative priming depends on prime-probe similarity: Evidence for episodic retrieval. Psychonomic Bulletin \& Review, 5, 107-113.

HARMS, L., \& BUNDESEN, C. (1983). Color segregation and selective attention in a nonsearch task. Perception \& Psychophysics, 33, 11-19.

Houghton, G., \& Tipper, S. P. (1994). A model of inhibitory mechanisms in selective attention. In D. Dagenbach \& T. H. Carr (Eds.), Inhibitory processess in attention, memory, and language (pp. 53-112). San Diego: Academic Press.

HumPHREYs, G. W. (1981). Flexibility of attention between stimulus dimensions. Perception \& Psychophysics, 30, 291-302.

KANWISHER, N., \& DrIVER, J. (1992). Objects, attributes, and visual attention: Which, what, and where. Current Directions in Psychological Science, 1, 26-31.

Kramer, A. F., Humphrey, D. G., Larish, J. F., Logan, G. D., \& STRAYER, D. L. (1994). Aging and inhibition: Beyond a unitary view of inhibitory processes in attention. Psychology \& Aging, 9, 491-512.

Kramer, A. F., \& JaCOBSON, A. (1991). Perceptual organization and focused attention: The role of objects and proximity in visual processing. Perception \& Psychophysics, 50, 267-284.

Kramer, A. F., Tham, M. P., \& Yeh, Y. Y. (1991). Movement and focused attention: A failure to replicate. Perception \& Psychophysics, 50, 537-546.

Kramer, A. F., Weber, T. A., \& Watson, S. E. (1997). Object-based attentional selection: Grouped arrays or spatially invariant representations? Comment on Vecera and Farah (1994). Journal of Experimental Psychology: General, 126, 3-13.

LAVIE, N. (1995). Perceptual load as a necessary condition for selective attention. Journal of Experimental Psychology: Human Perception \& Performance, 21, 451-468.

LAVIE, N., \& Driver, J. (1996). On the spatial extent of attention in objectbased visual selection. Perception \& Psychophysics, 58, 1238-1251.

Lavie, N., \& Fox, E. (1997). Perceptual load and negative priming. Manuscript submitted for publication.

MARR, D. (1982). Vision: A computational investigation into the human representation and processing of visual information. San Francisco: W. H. Freeman.

MaY, C. P., Kane, M. J., \& Hasher, L. (1995). Determinants of negative priming. Psychological Bulletin, 118, 35-54.

MiLleR, J. (1991). The flanker compatibility effect as a function of visual angle, attentional focus, visual transients, and perceptual load: A search for boundary conditions. Perception \& Psychophysics, 49, 270-288.

Moore, C. M. (1994). Negative priming depends on probe-trial conflict: Where has all the inhibition gone? Perception \& Psychophrsics, 56, 133-147.

NEILL, W. T. (1977). Inhibitory and facilitatory processes in selective attention. Journal of Experimental Psychology: Human Perception \& Performance, 3, 444-450.

NEILL, W. T. (1997). Episodic retrieval in negative priming and repetition priming. Journal of Experimental Psychology: Learning, Memory, \& Cognition, 23, 1291-1305.

Neill, W. T., \& Valdes, L. A. (1992). Persistence of negative priming: Steady state or decay? Journal of Experimental Psychology: Learning, Memory, \& Cognition, 18, 565-576.

NEILL, W. T., \& VAI.DES, L. A. (1996). Facilitatory and inhibitory as- 
pects of attention. In A. F. Kramer, M. G. H. Coles, \& G. D. Logan (Eds.), Converging operations in the study of visual selective attention (pp. 77-106). Washington, DC: American Psychological Association.

NeILl, W. T., Valdes, L. A., \& Terry, K. M. (1995). Selective attention and the inhibitory control of cognition. In F. N. Dempster \& C. J. Brainerd (Eds.), New perspectives on interference and inhibition in cognition (pp. 207-263). New York: Academic Press.

Neill, W. T., Valdes, L. A., Terry, K. M., \& Gorfein, D. S. (1992). Persistence of negative priming: II. Evidence for episodic trace retrieval. Journal of Experimental Psychology: Learning, Memory, \& Cognition, 18, 993-1000.

NeILl, W. T., \& WestberRY, R. L. (1987). Selective attention and the suppression of cognitive noise. Journal of Experimental Psychology: Learning, Memory, \& Cognition, 13, 327-334.

Posner, M. I. (1980). Orienting of attention. Quarterly Journal of Experimental Psychology, 32, 3-25.

Ruthruff, E., \& Miller, J. (1995). Negative priming depends on ease of selection. Perception \& Psychophysics, 57, 715-723.

SCHNEIDER, W. (1988). Micro Experimental Laboratory: An integrated system for IBM PC compatibles. Behavior Research Methods, Instruments, \& Computers, 20, 206-217.

TIPPER, S. P. (1985). The negative priming effect: Inhibitory priming by ignored objects. Quarterly Journal of Experimental Psychology, 37A, 571-590.

TIPPER, S. P., \& CRANSTON, M. (1985). Selective attention and priming: Inhibitory and facilitatory effects of ignored primes. Quarterly Journal of Experimental Psychology, 37A, 591-611.

TipPer, S. P., MacQueen, G. M., \& Brehaut, J. C. (1988). Negative priming between response modalities: Evidence for the central locus of inhibition in selective attention. Perception \& Psychophysics, 43, 45-52.

TIPPER, S. P., \& MILLIKEN, B. (1996). Distinguishing between inhibitionbased and episodic retrieval-based accounts of negative priming. In A. F. Kramer, M. G. H. Coles, \& G. D. Logan (Eds.), Converging operations in the study of visual selective attention (pp. 337-364). Washington, DC: American Psychological Association.

Tsal, Y., \& LAVIE, N. (1988). Attending to color and shape: The special role of location in selective visual processing. Perception \& Psychophysics, 44, 15-21.

van der Heijden, A. H. C., Kurvink, A. G., De Lange, L., De Leeuw, F., \& VAN DER GEEST, J. N. (1996). Attending to color with proper fixation. Perception \& Psychophysics, 58, 1224-1237.

VECERA, S. P. (1997). Grouped arrays versus object-based representations: Reply to Kramer et al. (1997). Journal of Experimental Psychology: General, 126, 14-18.

VECERA, S. P., \& FARAH, M. J. (1994). Does visual attention select objects or locations? Journal of Experimental Psychology: General, 123, 146-160.

\section{NOTES}

1. My thanks to an anonymous reviewer for suggesting this possibility.

(Manuscript received October 21, 1996; revision accepted for publication August 30, 1997.) 